Research Article

\title{
Distributed Load Shedding considering the Multicriteria Decision-Making Based on the Application of the Analytic Hierarchy Process
}

\author{
Nghia T. Le $\mathbb{D}^{1}{ }^{1}$ An T. Nguyen $\mathbb{D}^{1},{ }^{1}$ Thi Trang Hoang, ${ }^{2}$ Hoang Minh Vu Nguyen $\mathbb{D}^{3}{ }^{3}$ \\ Anh H. Quyen $\mathbb{D}^{1}{ }^{1}$ and Binh T. T. Phan ${ }^{4}{ }^{4}$ \\ ${ }^{1}$ Department of Electrical and Electronics Engineering, HCMC University of Technology and Education, \\ Ho Chi Minh 71313, Vietnam \\ ${ }^{2}$ Technology Faculty, Dong Nai Technology University, Bien Hoa 76116, Vietnam \\ ${ }^{3}$ HCMC University of Architecture, Ho Chi Minh 72407, Vietnam \\ ${ }^{4}$ Department of Electrical and Electronics Engineering, HCMC University of Technology, Ho Chi Minh 72506, Vietnam
}

Correspondence should be addressed to Nghia T. Le; trongnghia@hcmute.edu.vn

Received 14 May 2021; Revised 20 August 2021; Accepted 17 September 2021; Published 14 October 2021

Academic Editor: Zeljko Stevic

Copyright (C) 2021 Nghia T. Le et al. This is an open access article distributed under the Creative Commons Attribution License, which permits unrestricted use, distribution, and reproduction in any medium, provided the original work is properly cited.

\begin{abstract}
This paper shows an analytic hierarchy process (AHP) algorithm-based approach for load shedding based on the coordination of the load importance factor (LIF), the reciprocal phase angle sensitivity (RPAS), and the voltage electrical distance (VED) to rank the load buses. This problem is important from a power system point of view, and the AHP method is able to support the decisionmaking process in a simple and intuitive way in a three-criterion environment. This satisfies the multicriteria decision-making to meet economic-technical aspects. The ranking and distributed shedding power at each demand load bus are based on this combined weight. The smaller overall weights of the load buses show the lesser importance of the load bus, the smaller reciprocal phase angle sensitivity, and the closer voltage electrical distance. Therefore, these load buses cut a larger amount of capacity, and vice versa. By considering the generator control, the load shedding consists of the primary and secondary control features of the generators to minimize the load shedding capacity and restore the system frequency value back to the allowable range. The efficiency of the suggested load-shedding scheme was verified via the comparison with the under-frequency load shedding (UFLS). The latter result is that the load shedding power of the suggested approach is $22.64 \%$ lower than the UFLS method. The case studies are experienced on the IEEE 9-generator; the 37-bus system has proven its effectiveness.
\end{abstract}

\section{Introduction}

In the load-shedding issue, the ranking of loads according to the priority of shedding is essential for adjusting the power balance, restoring frequency to bring economic, technical efficiency to customers. Therefore, it is necessary to determine which loads need to be classified in the list of loads to be shed and their priority order. The ranking of these loads should satisfy many aspects that require an analysis of the economic and technical consequences. However, the calculation of economic and technical analysis is very complicated, and most power companies in the world still base on the evaluation of electrical system experts. However, it is very difficult for experts to prioritize these loads, especially when a load needs to be considered in many different criteria.

Studies on optimizing load shedding considering multiobjective constraints are mainly to solve the problem of minimizing the load shedding power. The proposal of a multiobjective optimization model considering load-shedding risk [1] is of interest to many researchers operating power systems. The multiobjective constraints are mostly technical constraints, such as conditions for power constraints of generating sets, power carrying capacity of the 
line, and the voltage at the nodes. However, in current times, the load shedding must meet many different goals, including achieving the technical requirements and economic goals including restoring frequency, load importance factor, the damage caused by power shedding, and priority level. The distributed shedding power at each demand load buses so that it is optimal and reduces the damage to the power supplier as well, such as customer power consumption. Solving this multicriteria load-shedding problem needs the application of algorithms for system experts.

The calculation of the load-shedding power is an essential factor to return the frequency back to the value within the permissible range and prevent the frequency degradation in the power system [2,3]. The load-shedding power is usually calculated based on frequency degradation [4], calculating the amount of load-shedding power; if the calculation is insufficient, it will not be possible to restore the frequency to the permissible value, and vice versa will cause excessive load shedding. Studies on load shedding mainly calculate it based on the rotation motion of the rotor [5]. However, these methods do not consider the actual operating conditions such as primary and secondary controls of generating sets.

The techniques of load shedding are distributed into three fundamental areas of study [6]: conventional load shedding, adaptive load shedding, and intelligent load shedding techniques. Conventional load shedding is a method of load shedding by using underfrequency loadshedding (UFLS) or under-voltage load-shedding (UVLS) relays. This is the most common method used for frequency control and voltage stabilization of the power grid. According to the IEEE standard, UFLS must be implemented quickly to prevent the electrical system frequency attenuation and power system blackout [7]. Many works used UFLS and UVLS [8-11]. These studies have the advantage of a low-cost, simple working principle. However, they have the main disadvantage that they do not estimate the amount of unbalanced power in the system. This result causes excessive load shedding, affects the quality of electricity, or leads to the discontinuation of electricity services or consumers [12]. In $[13,14]$, the high-priority loads were considered during load shedding, but the secondary frequency control was not added. Reference [15] showed the UFLS using decision trees to decide whether the load needs to be cut or not and the amount of load capacity to be cut. The decision tree was built based on the frequency derivative, the load demand, and the system's reserve capacity. However, this method has not considered the important factor of the load in the electricity system. The adaptive loadshedding method uses the swing rotor equation to calculate the amount of load shedding [5]. Rate of change of frequency (ROCOF) relay is used to perform load shedding [16]. The method proposed in [12] used both frequency deviation and voltage parameters to improve the accuracy of the frequency and voltage stability. In [17], a semi-adaptive multistage UFLS plan with ROCOF element and AHP method is proposed. The AHP method is based on two main criteria including the total amount of load shed and the minimum point of frequency response to rank the importance of load shedding. However, assessing the importance of loads based on the AHP algorithm has not been considered. In [18], the artificial neural network (ANN) and power flow tracing were used to evaluate the total active power imbalance. The load priority was considered in this study. However, the $0-1$ variable is introduced to represent. The load priority of the load at bus $k$ was allowed to be shed; the value of $a$ is set to 1 . Otherwise, the value of a was set to 0 . This shows that the baseload and the ranking of load shedding priority have not been considered in this situation.

The intelligent load-shedding methods include the application of intelligent algorithms such as artificial neural network (ANN) [19-21], adaptive neural-fuzzy inference system (ANFIS) [22, 23], fuzzy logic control (FLC) [24], genetic algorithm (GA) [25], and particle swarm optimization (PSO) [26, 27] to calculate and select the shed load. These approaches can easily solve nonlinear, multiobjective problems in power systems that conventional methods cannot solve with the desired speed and acceptable accuracy $[19,28]$. For ANN, the output is the total quantity of active power that needs to be cut. This output is not an actual signal because it does not determine the number of loads and the load capacity to be shed in each step. Multiobjective optimization methods using GA or PSO algorithms only have constraints on technical conditions. These methods do not have a combination of multiple methods including economic technical parameters when studying the load ranking. In [29], the weight coefficient in the load shedding objective equation was adjusted to satisfy the actual needs. Furthermore, reference [30] coordinated the optimization loadshedding method based on sensitivity analysis. The weighted sum of economic expense and equilibrium index was taken as the objective function to establish the load-shedding optimization model. However, this model has not considered the important factor of the load and has not yet ranked the load in the order of priority load.

This paper focuses on the coordination of various objectives during the load-ranking process. In this paper, a new load shedding method is presented based on the calculation of primary and secondary control of the generator to determine the minimum amount of shedding power. It coordinates criteria to consider the aspects to respond to load shedding in the direction of decision-making multicriteria. This satisfies the technical and economic factors to optimize the distribution of the power shedding at each load bus. There is an easier method for experts to approach the critical issues of load shedding criteria. When giving opinions, they often rely on technology characteristics and operating realities to be able to make verbal comments. Experts make it easy for a comparison of pairs and common languages like Load 1 is more important than Load 2, or Criterion 1 is more important than Criterion 2. In addition, the evaluation of the important rank of the load in the frequency control problem is also considered under many criteria with different importance levels. The paper proposes an approach based on consultation with experts when expressed in words. Each load will be considered under many criteria.

The efficiency of the suggested load-shedding technique was proved through the test on the 9-generator, 37-bus 
system. The calculations are evaluated with a traditional underfrequency load-shedding method. The results have shown that the suggested approach has a lower amount of load shedding capacity than the UFLS method. Therefore, the proposed method can minimize the damage and inconvenience caused to electricity customers. The recuperation time and rotor deviation angle are still guaranteed within the permissible values and sustained the power system stability. In addition, the proposed method demonstrates the combination of multimethod taking into account both technical and economic criteria that have not been carried out by previous studies. Therefore, in large disturbance situations such as large outage generators, this proposed method can be used to teach operators and improve their skills.

\section{Materials and Methods}

2.1. Calculate the Overall Weights and Rank the Load Buses to Load Shedding Based on the AHP Algorithm. It is supposed that there are $m$ loads to be shed in the electrical system diagram. These loads need to be ranked for load shedding based on coordination of three criteria including LIF, RPAS, and VED. The problem is that in the case of outage generators and load shedding is required, ranking and distributing the amount of load-shedding power to these loads require the satisfaction of multiple criteria simultaneously. To achieve that, it requires technical and economic consequences analysis. However, these calculations and analysis are very complicated and time-consuming. Therefore, it is necessary to collect reviews of power system experts in this regard. Experts easily give a verbal comment when comparing each pair of criteria and using common language, such as Criterion 1 is more important than Criterion 2. In this section, the AHP method is able to support the decision-making process in a simple and intuitive way in a three-criterion environment to calculate the overall weights of criteria and rank the load buses to load shedding. The ranking of the load buses is based on the AHP method which includes three stages: establishing the hierarchical structure, determining the weights of criteria, and calculating the overall weights.

\subsubsection{Stage 1: Establishing the Hierarchical Structure.} This step targets to solve the problem of the ranking of load buses into a hierarchical structure [31-34]. Accordingly, a three-level hierarchical structure is proposed for calculating the overall weights, as shown in Figure 1. In this study, three types of criteria are proposed: LIF, RPSA, and VED. The three criteria are described in detail in the following sections.

(1) First Criterion: The Reciprocal Phase Angle Sensitivity (RPAS) from the Load Buses to the Outage Generator. The concept of the RPAS between two buses is defined as follows [35-39]:

$$
D_{p}(i, j)=\left(J_{P \theta}^{-1}\right)_{i i}+\left(J_{P \theta}^{-1}\right)_{j j}-\left(J_{P \theta}^{-1}\right)_{j i}-\left(J_{P \theta}^{-1}\right)_{i j} .
$$

In the power system, the goal is to concentration on the priority of load shedding at the nearby outage generator location. To do this, the idea of the RPAS between two buses is applied. Two buses close to each other always have exceptionally little RPAS. The smaller the RPAS between the load buses and the outage generator, the closer the load bus is to the outage generator. Therefore, when a disturbance occurs in an area on the grid, adjusting the grid in the disturbance area will achieve the best effect. Thus, minimizing the control errors in the disturbance area will have little effect on other areas in the system. Additionally, in load shedding, the delineation of a serious disturbance and load shedding around the disturbance area make the impact of the disturbance on a smaller system a more effective loadshedding method.

The following steps show the calculation of the reciprocal phase angle sensitivity:

Step 1: Extract the Jacobian matrix $\left[J_{P \theta}\right]$

Step 2: Inverse elements in the Jacobian matrix $\left[J_{P \theta}\right]$, calculate the elements in the matrix $\left[J_{P \theta}^{-1}\right]$

Step 3: Apply formula (1) to calculate $D_{p(i, j)}$

The weight of the load bus based on the RPAS between the load bus and the outage generator is calculated by the following formula:

$$
W_{D_{P}(i, j)}=\frac{D_{P}(i, j)}{\sum_{1}^{m} D_{P}(i, j)},
$$

where $W_{D_{P}(i, j)}$ is the weight of the RPAS from the $i$-bus to the outage generator and $D_{P}(i, j)$ is the RPAS from the $i$-load bus to the outage generator.

(2) Second Criterion: The Voltage Electrical Distance (VED) from the Load Buses to the Outage Generator. The VED can be obtained by following steps [40-43]:

Step 1: Turn all generator buses into PQ buses for calculating $[\partial V / \partial Q]$.

Step 2: Calculate $[\partial V / \partial Q]$ in all buses. This value is the inverse of the Jacobian matrix that indicates the effect on a voltage variation at neighboring buses of reactive power injection at a bus.

$$
\Delta V_{i}=-[\partial V / \partial Q] \Delta Q_{j}=-J_{i j}^{-1} \Delta Q_{j}
$$

where $J_{i j}^{-1}$ is sensitivity matrix $\left[\partial V_{i} / \partial Q_{j}\right]$.

Step 3: Calculate $\alpha_{i j}$ using the sensitivity matrix of step 2 . The voltage changes in the bus $i$ due to voltage change in bus $j$ are as follows:

$$
\Delta V_{i}=\left[J_{i j}^{-1} / J_{j j}^{-1}\right] \Delta V_{j}=\alpha_{i j} \Delta V_{j}
$$

where $\alpha_{i j}$ is defined as $\left[J_{i j}^{-1} / J_{j j}^{-1}\right]$.

Step 4: Calculate the VED using $\left(\alpha_{i j} \times \alpha_{j i}\right)$, which is reflected by the symmetrical distance.

$$
D_{V}(i, j)=D_{V}(j, i)=-\log \left(\alpha_{i j} * \alpha_{j i}\right)
$$

where $\alpha_{j i}$ is defined as $\left[J_{i j}^{-1} / J_{j j}^{-1}\right]$. 


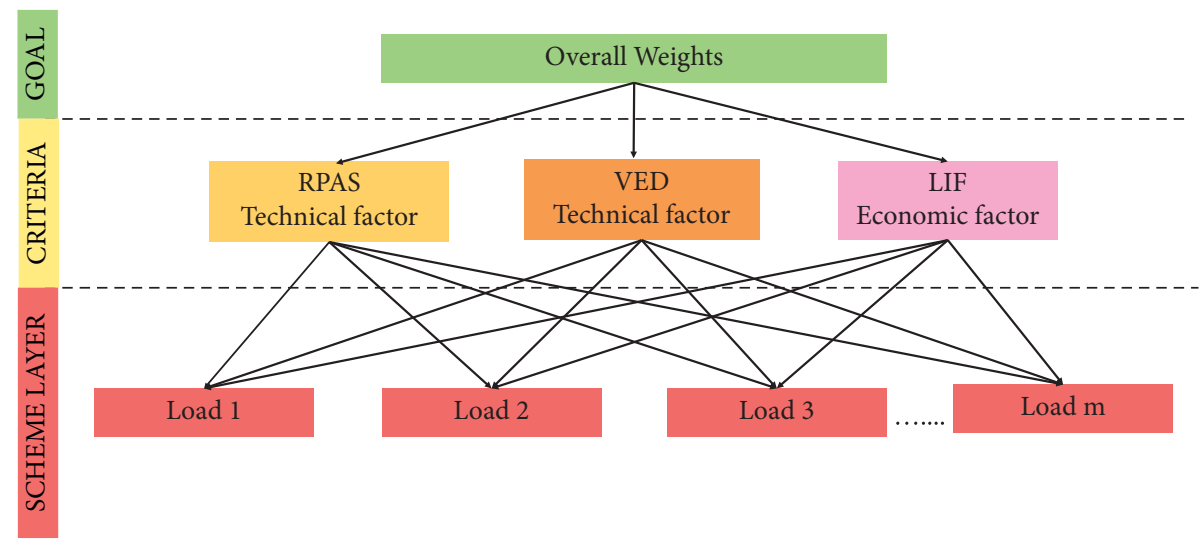

FIgURE 1: Three-level hierarchical structure for load buses ranking.

After calculating the VED, the weight of the load buses based on the VED between the load buses and the outage generator is calculated by the following formula:

$$
W_{D_{V}(i, j)}=\frac{D_{V}(i, j)}{\sum_{1}^{m} D_{V}(i, j)},
$$

where $W_{D_{P}(i, j)}$ is the weight of the VED from the $i$-load bus to the outage generator and $D_{V}(i, j)$ is the VED from the $i$ load bus to the outage generator.

The VED is the physical relationship between two buses in the power system. Formula (5) shows that the closer the distance, the smaller $D_{V}$ or the larger $\alpha_{i j}$. On the other hand, formula (4) evaluates the voltage interactions between bus $i$ and bus $j$. The bigger $\alpha_{i j}$ is, the greater the voltage attenuation at bus $i$ when a disturbance occurs at bus $j$. Thus, when an outage generator occurs, the amplitude of the voltage fluctuation near this generator is large, leading to an attenuation voltage at nodes with a small VED also increasing. To ensure the voltage profile returns to its stability margin, the amount of load shedding at each bus can be calculated on the principle that the smaller the VED, the larger the load shedding power, and vice versa. The relationship between the generator and the loads is shown in Figure 2.

With: $D_{V}(k, 1)<D_{V}(k, 2)<D_{V}(k, 3)<\ldots<D_{V}(k, n)$.

Prioritized load shedding: Load $1 \longrightarrow$ Load $2 \longrightarrow$ Load 3 $\longrightarrow \ldots \longrightarrow$ Load $n$.

(3) Third Criterion: The Load Importance Factor (LIF). The parameters of the LIF weight, $W_{\text {LIF }}$, were calculated by the fuzzy AHP algorithm and suggested to be in [34]. The LIF shows how important the loads are to each other when the assessor considers mainly the economic aspect. In other words, the larger the $W_{\text {LIF }}$ is, the more damage when load shedding is.

2.1.2. Stage 2: Determining the Weights of Criteria. Based on the established hierarchy structure, there are three steps to determine the weights of criteria. Firstly, pair-wise comparison or judgment matrices are formed to measure the relative importance of each two criteria. The pair-wise comparison scale proposed by Saaty [44] is applied, as showed in Table 1. A pair-wise comparison matrix is described by the following equation. The value of $p_{i j}$ is equal to the reciprocal of $p_{i j}$ in the pair-wise comparison matrix.

$$
P=\left[\begin{array}{cccc}
1 & p_{12} & \ldots & p_{1 n} \\
1 / p_{12} & 1 & \ldots & p_{2 n} \\
\ldots & \ldots & \ldots & \ldots \\
1 / p_{1 n} & 1 / p_{2 n} & \ldots & 1
\end{array}\right],
$$

where $P$ is a pair-wise comparison matrix and $p_{i j}$ is the importance of the $i$-th criteria relative to the $j$-th criteria.

Secondly, the largest eigenvalue and the eigenvector of a pair-wise comparison matrix are calculated. The relation among the largest eigenvalue, eigenvector, and pair-wise comparison matrix is defined by the following equation. The eigenvector is then normalized to obtain the weight vector of corresponding criteria.

$$
P \omega=\lambda_{\max } \cdot \omega
$$

where $P$ is a pair-wise comparison matrix, $\lambda_{\max }$ is the largest eigenvalue of the pair-wise comparison matrix, and $\omega$ is the corresponding eigenvector.

Thirdly, the consistency index and consistency ratio of a pair-wise comparison matrix are evaluated, as the inconsistency may happen due to subjective expert judgment. They are defined by the following equations. A pair-wise comparison matrix is satisfied if the stochastic consistency ratio, $\mathrm{CR}<0.10$.

$$
\begin{aligned}
\mathrm{CI} & =\frac{\lambda_{\max }-n}{n-1}, \\
C R & =\frac{\mathrm{CI}}{\mathrm{RI}},
\end{aligned}
$$

where CI is the consistency index of a pair-wise comparison matrix, $\mathrm{CR}$ is the consistency ratio of the matrix, RI is the random index of the matrix, $\lambda_{\max }$ is the largest eigenvalue of the matrix, and $n$ is the number of criteria in the matrix.

2.1.3. Stage 3: Calculating the Overall Scores. The overall score of each load bus is calculated by using equation (11). The higher the overall score of load bus is, the more 
TABLe 1: Pair-wise comparison scale of criteria.

\begin{tabular}{lcc}
\hline Numerical rating & Definition & Explanation \\
\hline 1 & Equal importance & Two criteria contribute equally to the goal \\
3 & Moderate importance & A criterion is favored slightly over the other \\
5 & Strong importance & A criterion is favored strongly over the other \\
7 & Very strong importance & A criterion is favored very strongly over the other \\
9 & Extreme importance & A criterion is favored extremely over the other \\
$2,4,6,8$ & Intermediate values between two adjacent scale values & Make a compromise between two adjacent judgments \\
\hline
\end{tabular}

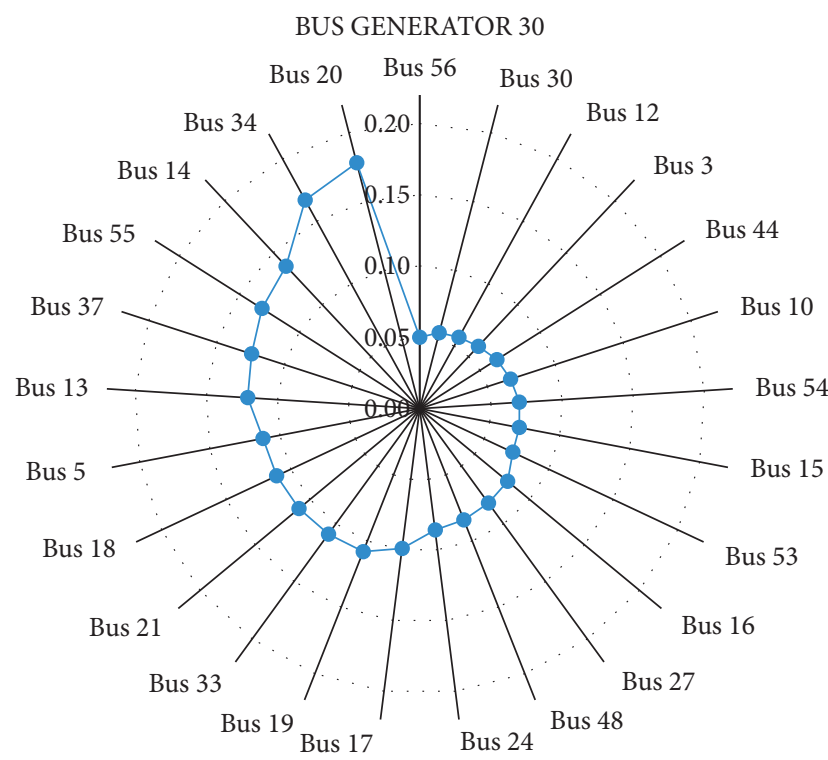

FIgURE 2: The VED relationship between generator 30 and the loads.

important the load bus is. It means that the higher the load is ranked, the less the load shedding distributed power to that load bus is done.

$$
\mu_{A_{i}{ }^{\tilde{n}}}\left(\mu_{1}, \mu_{2}, \mu_{i} \ldots, \mu_{n}\right)=\sum_{i=1}^{n} W_{i} W_{D, j},
$$

where $\mu_{A \sim}$ is the overall score of each load bus, $W_{i}$ is the weight of the $i$-th criterion, and $W_{D, j}$ are the values represented by $W_{\mathrm{LIF}}, W_{D_{v}(i, j)} W_{D_{P}(i, j)}$.

\subsection{Calculate the Minimum Load-Shedding Power and Dis-} tribute Load-Shedding Power at the Load Buses. After the overall weights are calculated for each load bus, the distributed shedding power at each demand load bus can be implemented according to the following flow chart in Figure 3.

Distributing the shedding power at the load buses requires two processes. In the first process, from the grid configuration and the location of the outage generator, the overall weights are calculated with the support of the AHP algorithm; the results are presented in equation (11). In the second process, when there is an outage generator and load shedding has to be implemented; the calculation of the load shedding power taking into account the process of primary and secondary frequency controls reduces the amount of shedding. This minimizes damages to customers due to power outages.

\subsubsection{Primary and Secondary Frequency Controls in Power} System. The process of frequency control when there is a disturbance in the power system consists of stages: level 1 control or primary frequency control and level 2 control or secondary frequency control [45]. In case after performing the level 2 control, the frequency has not returned to the allowable value, the load shedding control must be implemented to restore the frequency to the allowable value. The generator frequency control process includes primary and secondary frequency controls described in [46, 47]. The process of this control is shown in Figure 4.

In summary, in the case of an outage of the generator or a power imbalance between the load and the generator, the power system implements primary and secondary frequency controls. After the implementation of the secondary frequency control adjustment process, the electrical system's frequency has not yet recovered to the permissible value, the load shedding will be implemented to restore the frequency. This is the last mandatory solution to avoid grid blackout and power system collapse.

2.2.2. Establish the Minimum Load-Shedding Power. The calculation of the minimum load shedding power ensures the minimum amount of power is shed while restoring the power system frequency to the permissible value and minimize damage to electricity users. The computation takes into account the primary control and the secondary control of the generator group in accordance with the actual operation.

The relationship between the load power variations with frequency variation is determined by the following equation:

$$
\Delta P_{D}=-\frac{\Delta f}{f_{n}} \cdot P_{L} \cdot D,
$$

where $P_{L}$ is the active power of the load, $\Delta P_{D}$ is the change of load power according to frequency change, and $D$ is the percentage characteristic of the change of load according to the percentage change of frequency, $\mathrm{D}$ value ranges from $1 \%$ to $2 \%$. It is determined experimentally in power systems [48]. For example, a value of $D=2 \%$ means that a $1 \%$ change in frequency will cause a $2 \%$ change in load.

In the power system with $n$ generators and $m$ loads, when the power system has an outage of the generator, the primary frequency control of $(n-1)$ remaining generators is 


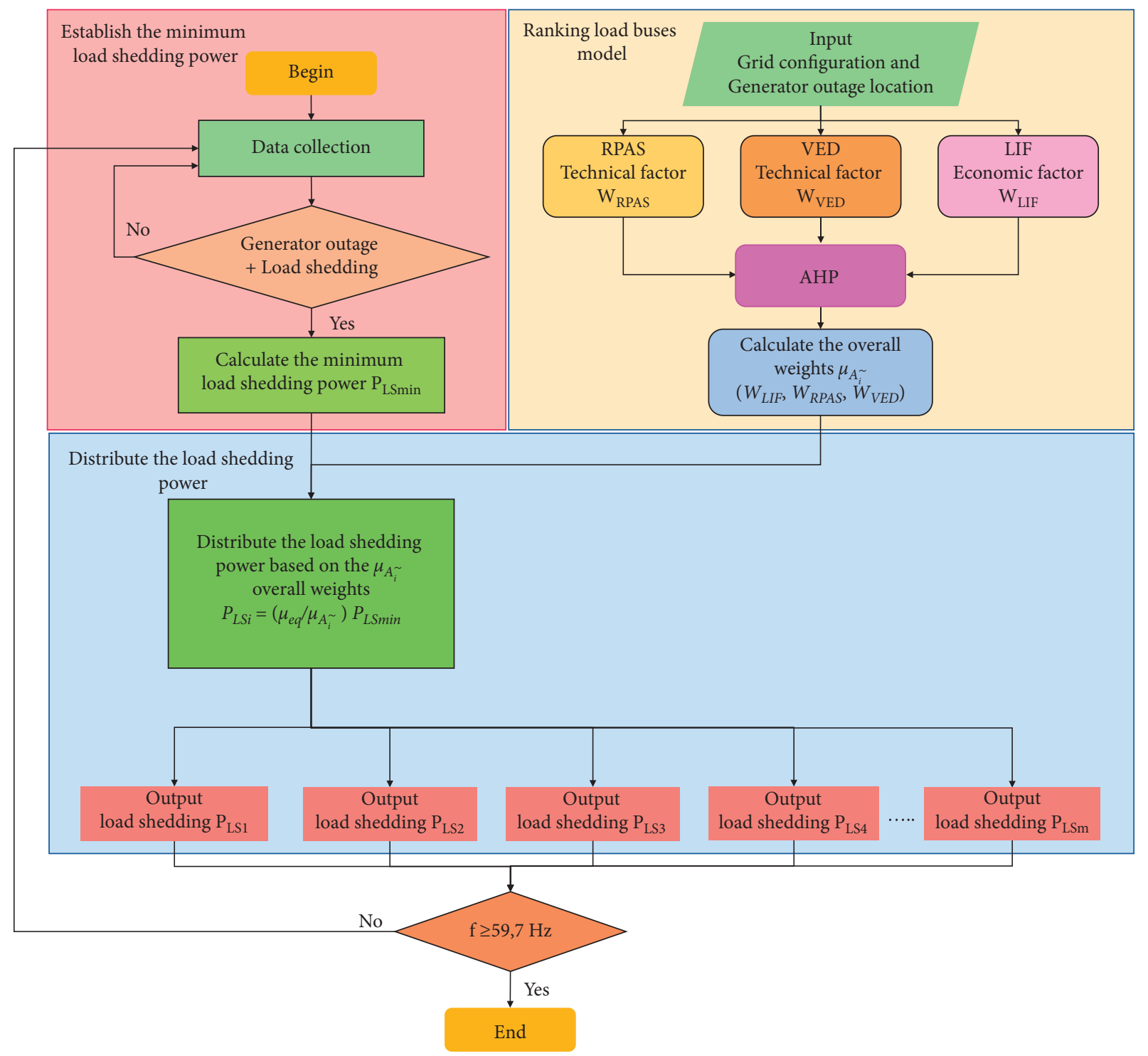

FIgURE 3: The flow chart of the load ranking of the shedding power process that satisfies many criteria.

performed with the amount of power adjustment according to the following expression:

$$
\sum_{i=1}^{n-1} \Delta P_{\text {Primary control }}=\sum_{i=1}^{n-1} \frac{-P_{G_{n, i}}}{R_{i}} \cdot \frac{\Delta f_{1}}{f_{0}},
$$

where $\Delta P_{\text {Primary control }}$ is the primary control power of the $i$-th generator, $P_{G, i}$ is the rated power of the $i$-th generator, $\Delta f_{1}=f_{1}-f_{0}$ is the frequency attenuation, and $f_{0}$ is the rated frequency of the power system.

When an outage of the generator occurs, the difference between the generator power and the $P_{\mathrm{L}}$ load power results in a frequency difference; in particular, the frequency is attenuated. The amount of load power depending on the frequency will be reduced by the amount of $\Delta P_{D}$, and the value of $\Delta P_{D}$ is presented in formula (12).

The status of power balance is presented in the following formulas:

$$
\begin{gathered}
P_{L}-\Delta P_{D}=\sum_{i=1}^{n-1} P_{G_{i}}+\sum_{i=1}^{n-1} \Delta P_{\text {Primary control }}, \\
P_{L}-\sum_{i=1}^{n-1} P_{G_{i}}=\Delta P_{D}+\sum_{i=1}^{n-1} \frac{-P_{G_{n, i}}}{R_{i}} \cdot \frac{\Delta f_{1}}{f_{0}}, \\
P_{L}-\sum_{i=1}^{n-1} P_{G_{i}}=-\left(\frac{\Delta f}{f_{0}}\right) \cdot P_{L} \cdot D+\sum_{i=1}^{n-1} \frac{-P_{G_{n, i}}}{R_{i}} \cdot \frac{\Delta f_{1}}{f_{0}}, \\
P_{L}-\sum_{i=1}^{n-1} P_{G_{i}}=-\left(\frac{\Delta f_{1}}{f_{0}}\right)\left(P_{L} \cdot D+\sum_{i=1}^{n-1} \frac{P_{G_{n, i}}}{R_{i}}\right) .
\end{gathered}
$$

Set $\Delta P_{L}=P_{L}-\sum_{i=1}^{n-1} P_{G_{i}}$ and $\beta=P_{L} \cdot D+\sum_{i=1}^{n-1} P_{G_{n i}} / R_{i}$. From formula (17), we have 


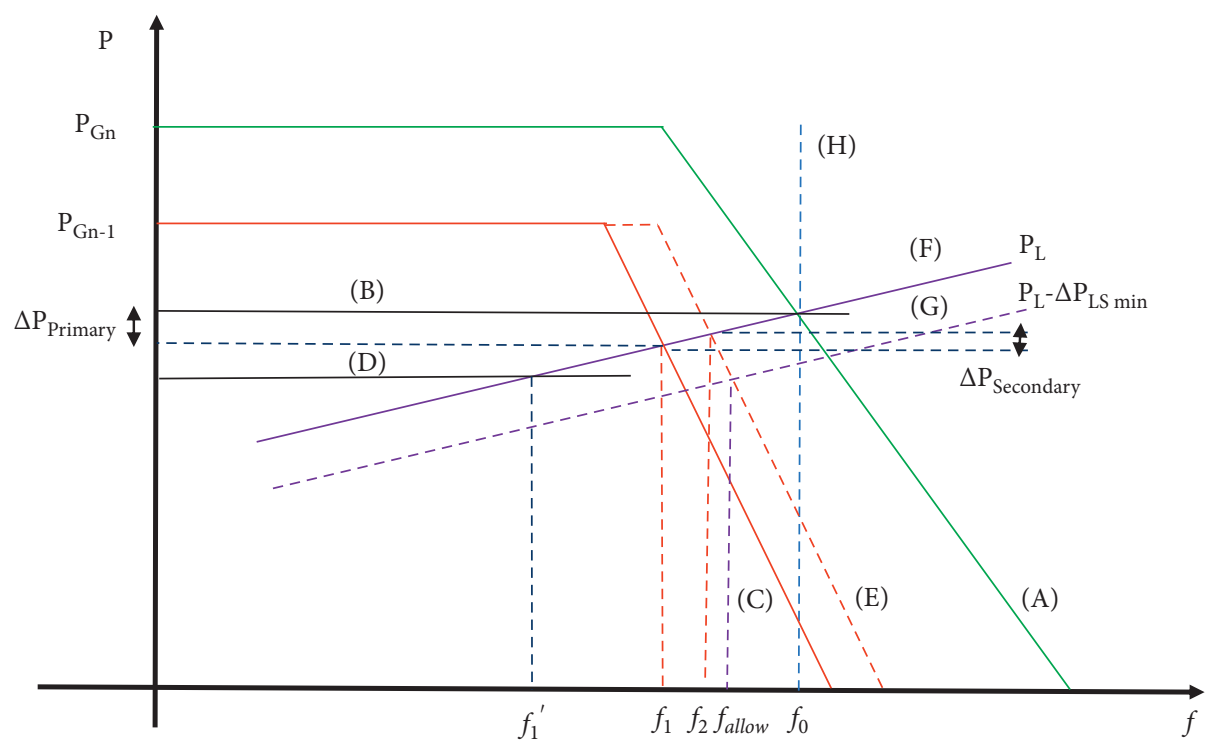

FIgURE 4: The relationship between frequency deviation and output power deviation [34]. Characteristic lines (A), (C), and (E) show the characteristic of the output power of a generator within a governor relating to the normal operating case, after the outage of the generator and after controlling the primary and secondary; characteristic lines (F) and (G) show the characteristic of the load power in the normal operating conditions and during load shedding, respectively; and characteristic lines (B) and (D) show the characteristic of the output power of a generator without a governor corresponding to the normal operating case, after the outage of the generator. $P G_{n}$ and $P G_{n-1}$ are the total value of the output power in the normal operating conditions and during the outage of the generator, respectively. $f_{0}$ is the rated frequency in the normal operating conditions. $f_{1}^{\prime}$ is the frequency when the outage of the generator (in case of the generator without a governor); $f_{2}$ is the frequency of the system after the primary and secondary control; and $f_{\text {allow }}$ is the restored frequency $(59.7 \mathrm{~Hz}$ for power grids with a rated frequency of $60 \mathrm{~Hz}$ ).

$$
\Delta P_{L}=\frac{-\Delta f_{1}}{f_{n}} \cdot \beta .
$$

In the case of considering the power of the secondary control to restore the frequency, the new status of power balance with the new frequency value $f_{2}$, equation (14) becomes:

$$
P_{L}-\Delta P_{D}=\sum_{i=1}^{n-1} P_{G_{i}}+\sum_{i=1}^{n-1} \Delta P_{\text {Primary control }}+\Delta P_{\text {Secondary control max }},
$$

where $\Delta P_{\text {Secondary control max }}$ is the maximum amount of secondary control power generated by the power system. This amount of secondary control power is determined by the following equation:

$$
\Delta P_{\text {Secondary control max }}=\sum_{j=1}^{m}\left(P_{G m, j}-\Delta P_{\text {Primary control, } j}\right),
$$

where $P_{G m, j}$ is the maximum generating power of the secondary frequency control generator $j$ and $\Delta P_{\text {Primary control, } j}$ is the primary control power of the secondary control generator $j$.

After including the secondary control process and the system frequency has not yet restored to the fallow the allowable value, then load shedding is required to recover the frequency; the minimum amount of load shedding power $P_{L S m i n}$ is calculated by the following equations:

$$
\begin{aligned}
P_{L}-\Delta P_{D}-P_{L S \text { min }} & =\sum_{i=1}^{n-1} P_{G_{i}}+\sum_{i=1}^{n-1} \Delta P_{\text {Primary control }}+\Delta P_{\text {Secondary control max }}, \\
\Delta P_{L S \text { min }} & =P_{L}-\Delta P_{D}-\sum_{i=1}^{n-1} P_{G_{i}}-\sum_{i=1}^{n-1} \Delta P_{\text {Primary control }}-\Delta P_{\text {Secondary control max }}, \\
\Delta P_{L S \text { min }} & =P_{L}-\sum_{i=1}^{n-1} P_{G_{i}}+\frac{\Delta f_{c p}}{f_{0}} \cdot P_{L} \cdot D+\sum_{i=1}^{n-1} \frac{P_{G_{n, i}}}{R_{i}} \cdot \frac{\Delta f_{\text {allow }}}{f_{0}}-\Delta P_{\text {Secondary control max }},
\end{aligned}
$$


where $\Delta f_{\text {allow }}=f_{0}-f_{\text {allow }}$ is the allowable frequency attenuation.

Formula (22) is abbreviated into the following formula:

$$
\Delta P_{L S \min }=\Delta P_{L}+\frac{\Delta f_{\text {allow }}}{f_{0}} \cdot \beta-\Delta P_{\text {Seconda } r y \text { control max }} \text {. }
$$

2.2.3. Distribute Load-Shedding Power at the Load Buses. After calculating the overall weights and the $P_{L S \text { min }}$, the load-shedding power at each load bus can be distributed in the same way as the principle of load sharing in the parallel circuit as follows:

$$
P_{L S i}=\frac{\mu_{e q}}{\mu_{A_{i}^{\sim}}} \cdot P_{L S \min }
$$

with

$$
\mu_{e q}=\frac{1}{\sum_{i=1}^{n} 1 / \mu_{A_{i}^{\sim}}}
$$

where $P_{L S i}$ is the amount load shedding power at the buses, $\mu_{e q}$ is the equivalent weight of all load buses, $\mu_{A_{i}}$ is the overall weights at the $i$-th bus, and $P_{L S \min }$ is the total minimum load shedding power.

2.3. Case Studies. The efficiency of the suggested approach is experienced on the IEEE 37-bus 9-generator system [47, 49], which is shown in Figure 5. All test cases are simulated using PowerWorld GSO 19 software. The calculations are compared with the traditional load shedding method using an underfrequency load-shedding relay.

In the studied case, the generator JO345 \# 1 (bus 28) is facing an outage and disconnected from the grid. Using formula (18), the established frequency value is calculated when the JO345 \# 1 generator (bus 28) faces an outage at $59.6 \mathrm{~Hz}$. The frequency value after the outage of generator JO345 \# 1 (bus 28) is less than the allowed value.

Therefore, it is important to execute the process of the generator control and re-establish frequency. The primary frequency control is performed automatically. The reaction of the governor is performed immediately after the generator JO345 \# 1 (bus 28) has been outage. The primary control power values for each generator turbine are shown in Table 2.

Because the recovery frequency is less than the allowed value, the secondary frequency control process should be implemented after the primary control. Secondary standby generator control power will be mobilized to perform secondary control. In the IEEE 37-bus 9-generator power system diagram, the SLACK 345 (SLACK bus) was chosen as the secondary frequency control generator. In this case, using equation (20), the amount of secondary control power calculated is $10.72 \mathrm{MW}$. A graphical simulation of the frequency of the system after the implementation of the secondary control is illustrated in Figure 6.

$$
\begin{aligned}
\Delta P_{L S \text { min }} & =\Delta P_{L}+\frac{\Delta f_{p}}{f_{0}} \cdot \beta-\Delta P_{\text {Secondary control max }} \\
\Delta P_{L} & =P_{L}-\sum_{i=1}^{n-1} P_{G_{i}}=9.5394-8.31780=1.2216 \\
\beta & =P_{L} \cdot D+\sum_{i=1}^{n-1} \frac{P_{G i}}{R_{i}}=9.5394 \times 0.02+187.4=187.590788 \\
\Delta P_{L S \min } & =1.2216+\frac{(-0.3)}{60} \times 187.590788-0.1072=0.1764 \mathrm{pu}
\end{aligned}
$$

Thus, after carrying out the secondary control process, the recovery frequency is $59.66 \mathrm{~Hz}$ and has not been back to the allowed value. Therefore, the ultimate solution is load shedding to restore the frequency to the allowable value. Application of formula (24) calculates the minimum amount of load shedding power to restore the frequency to the permissible value.

In a $60 \mathrm{~Hz}$ power system, the permissible frequency attenuation $\Delta$ fallow is $0.3 \mathrm{~Hz}$.
$\Delta f_{\text {allow }}=-0.3 \mathrm{~Hz}$. Therefore, when calculated in relative units (pu), then $\Delta f_{\text {allow }}=-0.3 / 60(\mathrm{pu})$.

In summary, the minimum load shedding power $P_{L S m i n}$ is $17.64 \mathrm{MW}$.

We implemented the same calculation steps above for a few other case studies. We calculated the value of the system frequency, the amount of primary and secondary control power and the load power to be reduced. Calculation results for these case studies are shown in Table 3. 


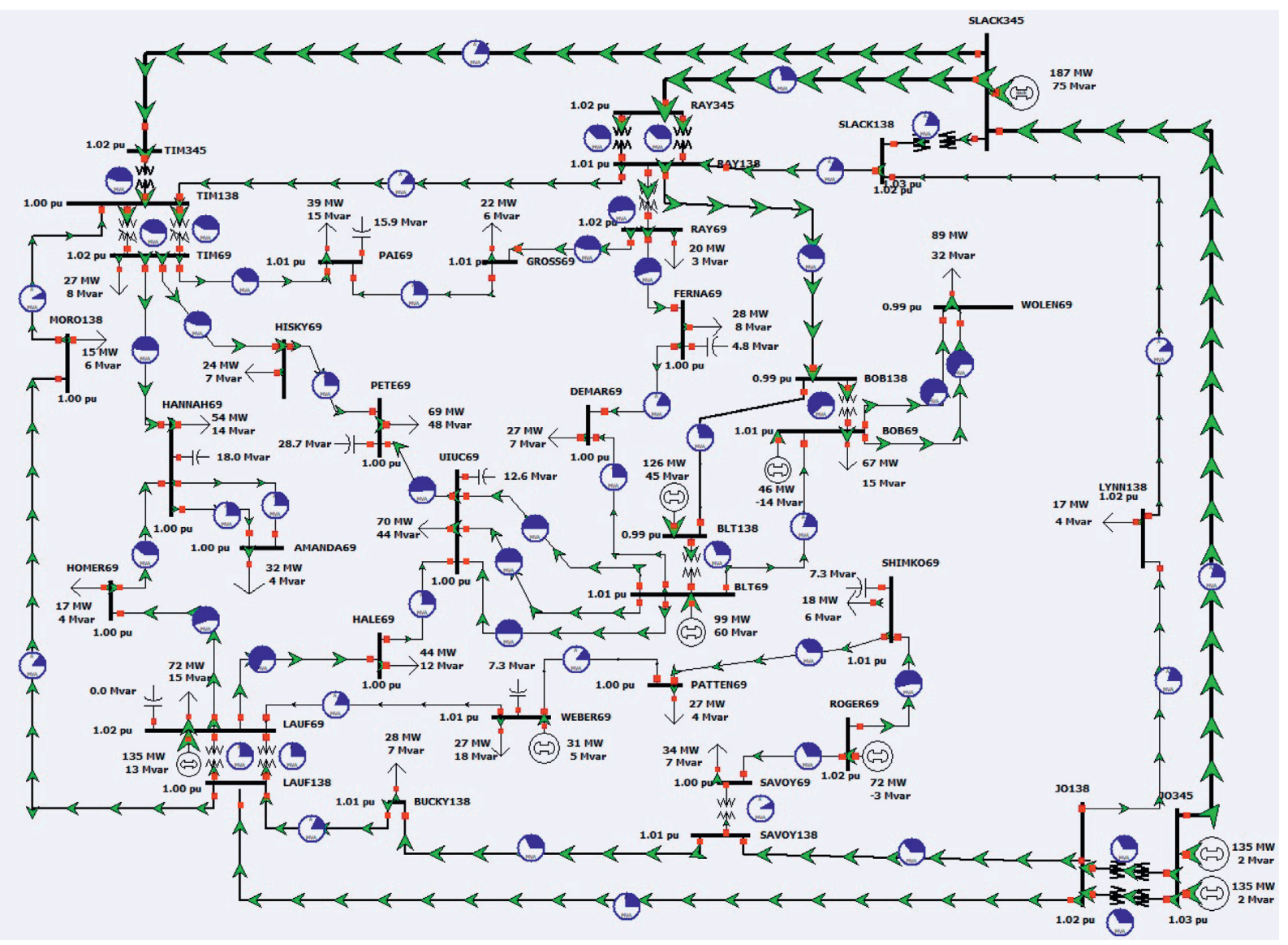

FIgURE 5: The IEEE 37-bus 9-generator system [47, 49].

TABLE 2: The parameter values and primary control power of the generator.

\begin{tabular}{|c|c|c|c|c|c|c|}
\hline Number of generator & Name of generator & $P_{G}(\mathrm{MW})$ & $P_{G}(\mathrm{pu})$ & $\mathrm{R}$ & $\Delta P_{\text {Primary control }}(\mathrm{pu})$ & $P_{G, n} / R$ \\
\hline 1 & WEBER69 & 31.5 & 0.315 & 0.05 & 0.035 & 7 \\
\hline 2 & JO345\#1 & 0 & 0 & 0.05 & 0 & 0 \\
\hline 3 & JO345\#2 & 135 & 1.35 & 0.05 & 0.15 & 30 \\
\hline 4 & SLACK345 & 187.2 & 1.872 & 0.05 & 0.22 & 44 \\
\hline 5 & LAUF69 & 135 & 1.35 & 0.05 & 0.15 & 30 \\
\hline 6 & BOB69 & 46 & 0.46 & 0.05 & 0.052 & 10.4 \\
\hline 7 & ROGER69 & 72 & 0.72 & 0.05 & 0.08 & 16 \\
\hline 8 & BLT138 & 126 & 1.26 & 0.05 & 0.14 & 28 \\
\hline 9 & BLT69 & 99 & 0.99 & 0.05 & 0.11 & 22 \\
\hline Total & & 831.7 & 8.317 & & 0.937 & 187.4 \\
\hline
\end{tabular}

The results of these calculations are the basis for the distribution of the amount of load-shedding power at the load buses based on the overall weights of the criteria.

After computing the minimum amount of load-shedding power, the next step calculates the load importance factor (LIF), the reciprocal phase angle sensitivity (RPAS), and the voltage electrical distance (VED). Using formulas (2) and (6), calculate the reciprocal phase angle sensitivity (RPAS) and the voltage electrical distance (VED). The parameters of the load importance factor (LIF) were calculated by fuzzy AHP algorithm and published by the authors in [34].
The overall weights for multimethod coordination criteria will be calculated using theory at stage 2 : determining the weights of criteria section and expert opinion, obtaining $\mathrm{P}$ matrix as follows:

$$
P=\left[\begin{array}{ccc}
1 & 3 & 2 \\
1 / 3 & 1 & 1 / 2 \\
1 / 2 & 2 & 1
\end{array}\right] .
$$

The eigenvector is calculated based on the matrix $P$; its value is shown below: 


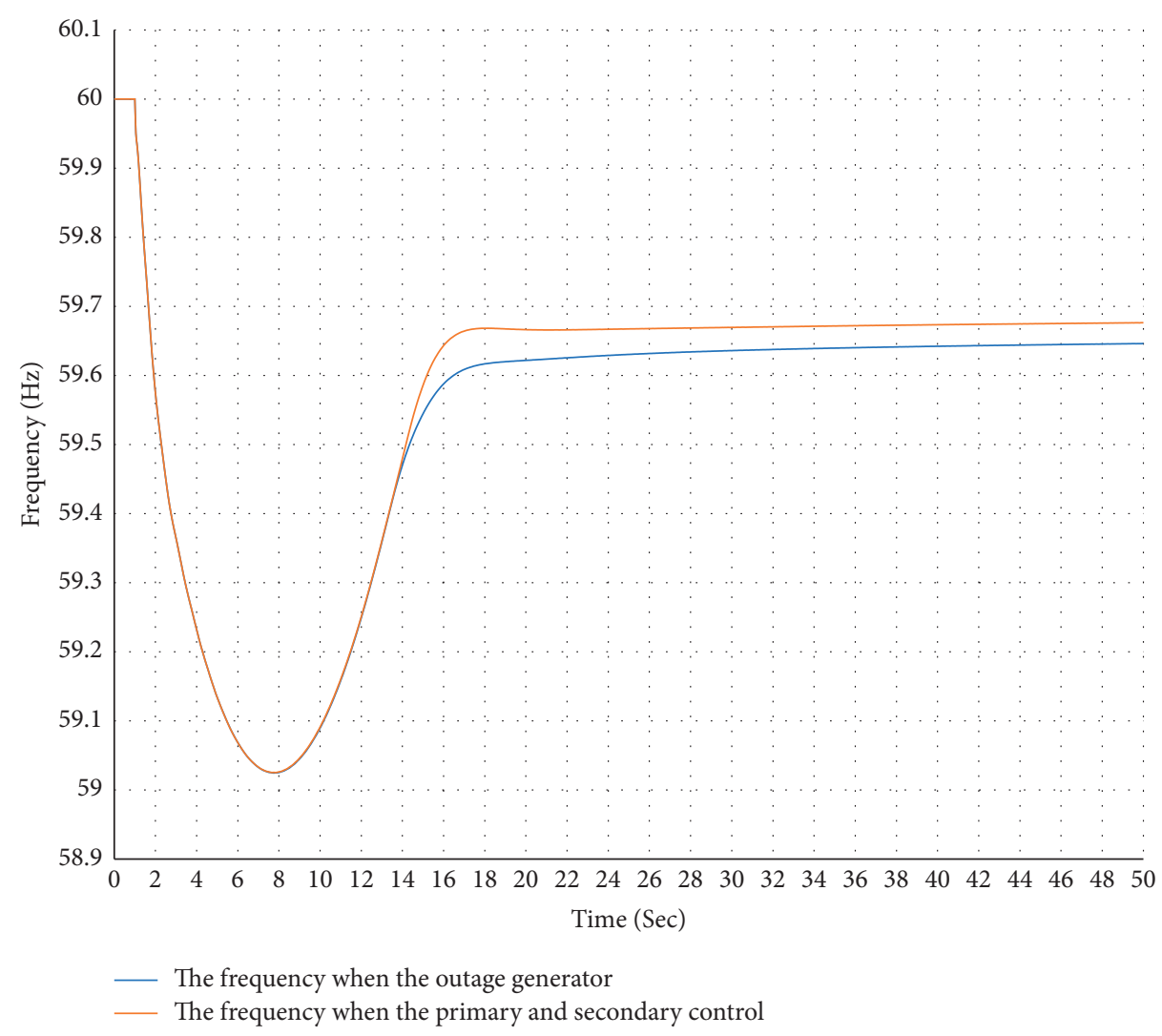

Figure 6: The frequency of the system when the JO345\#1 generator outages.

Table 3: The results of generator outage case study.

\begin{tabular}{lccc}
\hline Generator outage & Frequency after generator outage $(\mathrm{Hz})$ & Frequency within the permissible range & Shed load $(\mathrm{MW})$ \\
\hline WEBER69 & 59.97 & Yes & 0 \\
JO345\#1 & 59.56 & No & 38.57 \\
JO345\#2 & 59.56 & No & 38.57 \\
SLACK345 & 59.62 & No & 13.89 \\
LAUF69 & 59.86 & Yes & 0 \\
BOB69 & 59.79 & Yes & 0 \\
ROGER69 & 59.61 & No & 18.2 \\
BLT138 & 59.70 & Yes & 0 \\
\hline
\end{tabular}

$$
W=\left[W_{1}, W_{2}, W_{3}\right]^{T}=[0.53962 ; 0.16342 ; 0.29696]^{T} .
$$

Equations (8)-(10) are used to calculate the largest eigenvalues $\left(\lambda_{\max }\right)$, the consistency index $(\mathrm{CI})$, and the stochastic consistency ratio (CR), respectively. The calculation results are presented as follows:

$$
\begin{aligned}
\lambda_{\max } & =3.009, \\
\mathrm{CI} & =0.0046, \\
\mathrm{CR} & =0.0079 .
\end{aligned}
$$

The above results show that the values of stochastic consistency ratio $\mathrm{CR}=0.00775<0.1$, so the proposed judgment matrix is reasonable.
After obtaining the weighted values of the criteria, the next step applies formula (11) to determine the values of the overall weights of each load bus and applies formula (25) to calculate the amount of power needed to be shed at each busload; the values are shown in Table 4 and Figure 7. The smaller overall weights of the load bus indicate that the load bus is of minor LIF, the RPAS is small, and the VED is small and, therefore, that the load will prioritize the shedding load with a large amount of load shedding power, and vice versa.

The suggested approach is compared to an underfrequency load-shedding relay approach. These values are shown in Table 5 [34].

It can be seen that the proposed load-shedding method has less amount of shedding (65.19 MW) than the UFLS, thereby minimizing the damage caused by power outages a lot. Simultaneously, satisfying the goal of combining a variety of economic and technical methods: The Load Importance Factor 
TABLE 4: Ranking of load shedding and the amount of load-shedding power at buses when the JO345\#1 (bus 28) generator outage.

\begin{tabular}{|c|c|c|c|c|c|c|c|c|}
\hline $\begin{array}{l}\text { Ranking of load } \\
\text { shedding }\end{array}$ & Bus & RPAS & VED & $\begin{array}{l}\text { Load importance } \\
\text { factor }\left(W_{\text {LIF }}\right)\end{array}$ & $\begin{array}{l}\text { Weight of RPAS } \\
\left(W_{\text {RPAS }}\right)\end{array}$ & $\begin{array}{l}\text { Weight of VED } \\
\left(W_{\mathrm{VED}}\right)\end{array}$ & $\begin{array}{c}\text { Overall weights } \\
\left(\mu_{A_{i}{ }^{-}}\right)\end{array}$ & $\begin{array}{l}\text { Shed load } \\
\text { (MW) }\end{array}$ \\
\hline 1 & $\begin{array}{c}\text { Bus } \\
03\end{array}$ & 0.06046 & 2.98914 & 0.00012 & 0.02513 & 0.03331 & 0,01406 & 1,33759 \\
\hline 6 & $\begin{array}{c}\text { Bus } \\
05\end{array}$ & 0.11244 & 3.39848 & 0.00012 & 0.04674 & 0.03787 & 0,01895 & 0,99271 \\
\hline 9 & $\begin{array}{c}\text { Bus } \\
10\end{array}$ & 0.06680 & 4.40264 & 0.00164 & 0.02777 & 0.04906 & 0,01999 & 0,94090 \\
\hline 3 & $\begin{array}{c}\text { Bus } \\
12\end{array}$ & 0.05650 & 3.49661 & 0.00211 & 0.02349 & 0.03896 & 0,01655 & 1,13679 \\
\hline 13 & $\begin{array}{c}\text { Bus } \\
13\end{array}$ & 0.12095 & 4.80471 & 0.00388 & 0.05028 & 0.05354 & 0,02621 & 0,71773 \\
\hline 10 & $\begin{array}{c}\text { Bus } \\
14\end{array}$ & 0.13660 & 3.13791 & 0.00359 & 0.05678 & 0.03497 & 0,02160 & 0,87077 \\
\hline 5 & $\begin{array}{c}\text { Bus } \\
15\end{array}$ & 0.07069 & 3.66261 & 0.00236 & 0.02939 & 0.04081 & 0,01820 & 1,03365 \\
\hline 8 & $\begin{array}{c}\text { Bus } \\
16\end{array}$ & 0.08001 & 3.80214 & 0.00427 & 0.03326 & 0.04237 & 0,02032 & 0,92565 \\
\hline 21 & $\begin{array}{c}\text { Bus } \\
17\end{array}$ & 0.09936 & 4.31684 & 0.05642 & 0.04130 & 0.04810 & 0,05148 & 0,36537 \\
\hline 23 & $\begin{array}{c}\text { Bus } \\
18\end{array}$ & 0.11118 & 3.72396 & 0.18097 & 0.04621 & 0.04150 & 0,11753 & 0,16004 \\
\hline 22 & $\begin{array}{c}\text { Bus } \\
19\end{array}$ & 0.10774 & 4.56991 & 0.09891 & 0.04478 & 0.05092 & 0,07581 & 0,24810 \\
\hline 24 & $\begin{array}{c}\text { Bus } \\
20\end{array}$ & 0.17781 & 3.21071 & 0.19005 & 0.07391 & 0.03578 & 0,12526 & 0,15017 \\
\hline 25 & $\begin{array}{c}\text { Bus } \\
21\end{array}$ & 0.10988 & 4.32333 & 0.19508 & 0.04568 & 0.04818 & 0,12704 & 0,14806 \\
\hline 7 & $\begin{array}{c}\text { Bus } \\
24\end{array}$ & 0.08637 & 3.53451 & 0.00418 & 0.03590 & 0.03939 & 0,01982 & 0,94898 \\
\hline 16 & $\begin{array}{l}\text { Bus } \\
27\end{array}$ & 0.08158 & 3.83314 & 0.02274 & 0.03391 & 0.04271 & 0,03050 & 0,61677 \\
\hline 2 & $\begin{array}{c}\text { Bus } \\
30\end{array}$ & 0.05542 & 1.93331 & 0.01184 & 0.02304 & 0.02154 & 0,01655 & 1,13661 \\
\hline 4 & $\begin{array}{c}\text { Bus } \\
33\end{array}$ & 0.10895 & 2.52799 & 0.00337 & 0.04529 & 0.02817 & 0,01758 & 1,06978 \\
\hline 18 & $\begin{array}{c}\text { Bus } \\
34\end{array}$ & 0.16743 & 3.22803 & 0.02305 & 0.06960 & 0.03597 & 0,03450 & 0,54529 \\
\hline 12 & $\begin{array}{c}\text { Bus } \\
37\end{array}$ & 0.12353 & 3.82862 & 0.00339 & 0.05135 & 0.04266 & 0,02289 & 0,82173 \\
\hline 15 & $\begin{array}{c}\text { Bus } \\
44\end{array}$ & 0.06433 & 2.56398 & 0.03384 & 0.02674 & 0.02857 & 0,03112 & 0,60451 \\
\hline 17 & $\begin{array}{c}\text { Bus } \\
48\end{array}$ & 0.08365 & 4.05141 & 0.02334 & 0.03477 & 0.04515 & 0,03169 & 0,59364 \\
\hline 14 & $\begin{array}{c}\text { Bus } \\
53\end{array}$ & 0.07244 & 4.01952 & 0.01916 & 0.03011 & 0.04479 & 0,02856 & 0,65857 \\
\hline 19 & $\begin{array}{c}\text { Bus } \\
54\end{array}$ & 0.07037 & 3.72225 & 0.04441 & 0.02925 & 0.04148 & 0,04106 & 0,45812 \\
\hline 20 & $\begin{array}{c}\text { Bus } \\
55\end{array}$ & 0.13139 & 4.64896 & 0.04441 & 0.05462 & 0.05181 & 0,04827 & 0,38967 \\
\hline 11 & $\begin{array}{c}\text { Bus } \\
56\end{array}$ & 0.04985 & 2.00815 & 0.02675 & 0.02072 & 0.02238 & 0,02447 & 0,76880 \\
\hline & Total & & & 1 & 1 & 1 & 1 & 17.64 \\
\hline
\end{tabular}

(economic), the Reciprocal Phase Angle Sensitivity, and the Voltage Electrical Distance. Here, the recovery frequency value of the proposed method is lower than the UFLS method. However, this value is still within the allowable parameters and acceptable range $(59.7 \mathrm{~Hz})$. Moreover, the voltage value and the recovery time of the rotor angle after load shedding are better quality than before the load shedding.

The frequency, rotor angle, and voltage comparison between the proposed method and the UFLS method are presented in Figures $8-10$. 


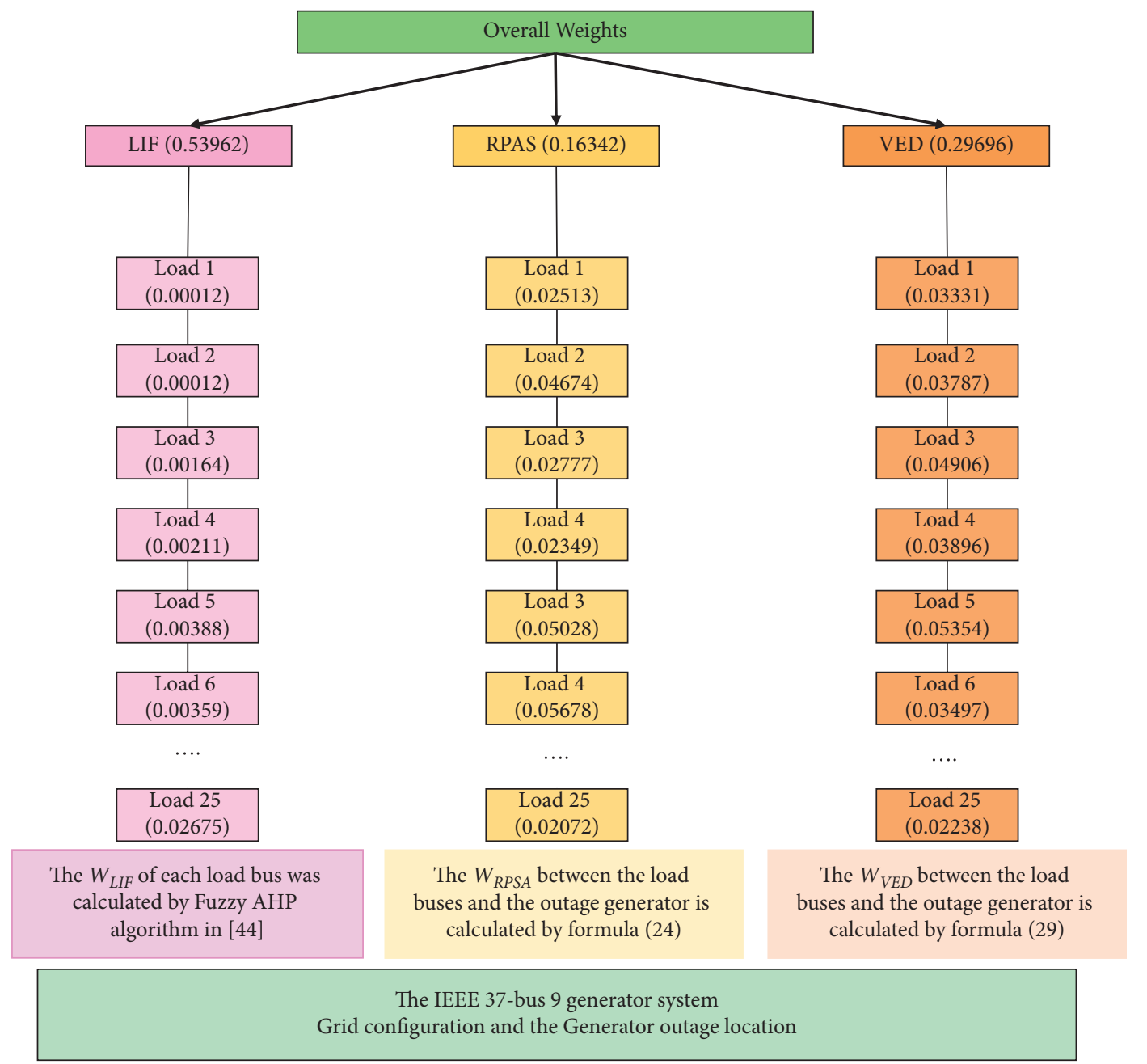

FIGURE 7: The value of the weights in the IEEE 37-bus 9-generator system hierarchy structure.

TABLE 5: The UFLS scheme using load-shedding table [47].

\begin{tabular}{lcccc}
\hline $\begin{array}{l}\text { The steps } \\
\text { UFLS }\end{array}$ & $\begin{array}{c}\text { Frequency } \\
(\mathrm{Hz})\end{array}$ & $\begin{array}{c}\text { Time delay } \\
(\mathrm{s})\end{array}$ & $\begin{array}{c}\text { The amount of load shedding (the percent of total } \\
\text { load) }(\%)\end{array}$ & $\begin{array}{c}\text { The total amount of load shedding } \\
(\%)\end{array}$ \\
\hline A & 59.7 & 0.28 & 9 & 9 \\
B & 59.4 & 0.28 & 7 & 16 \\
C & 59.1 & 0.28 & 6 & 23 \\
D & 58.8 & 0.28 & 5 & 34 \\
E & 58.5 & 0.28 & 7 & 41 \\
F & 58.2 & 0.28 & 5 & 46 \\
J & 59.4 & 10 & & 7 \\
\hline
\end{tabular}

\section{Discussion}

The AHP method is quite simple and intuitive in a threecriterion environment. It easily supports the calculation of the overall weights of the criteria. In this study, the pair-wise comparison matrixes are formed by one expert. If there are many experts, some group decision-making methods can be accepted to aggregate the pair-wise comparison matrixes determined by these experts [50]. For example, a weighted geometric mean method can be used as a tool to do this aggregation. In addition, if the value of the pair-wise comparison is uncertain, the combined use of AHP with fuzzy methods is also one of the possible solutions [34].

For a very large power system, when there is a failure of one generator, the space of influence on the technical parameters of the entire grid is negligible. It is only significant when very serious problems occur and the large-power system is divided into smaller systems or islands. In particular, in the larger power grid, areas far from the outage generator are not affected much. It only affects the areas near and around the outage generator. Therefore, this situation does not need to take the entire grid into consideration. In 


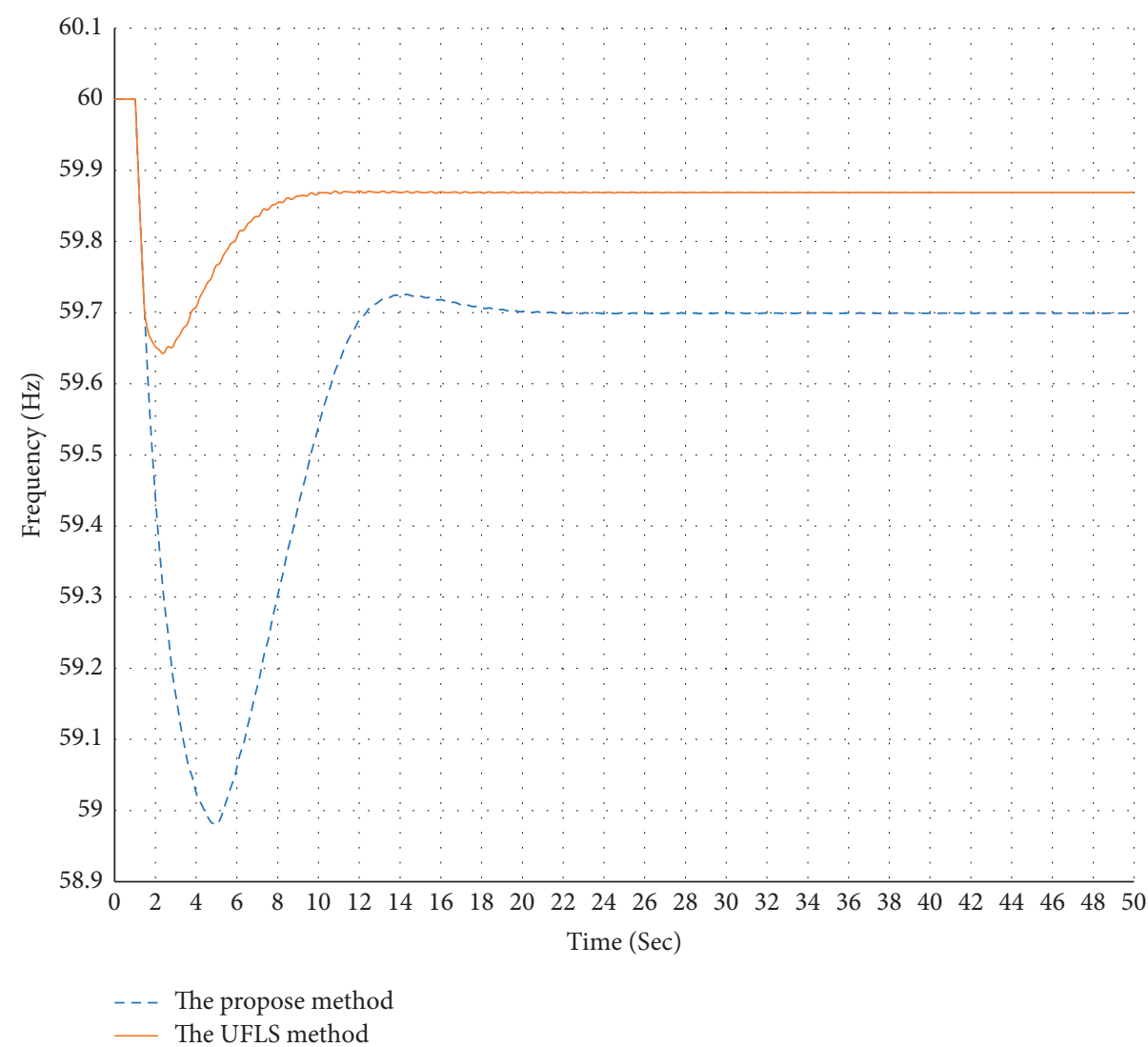

FIgURE 8: The frequency comparison between the proposed method and the traditional met.

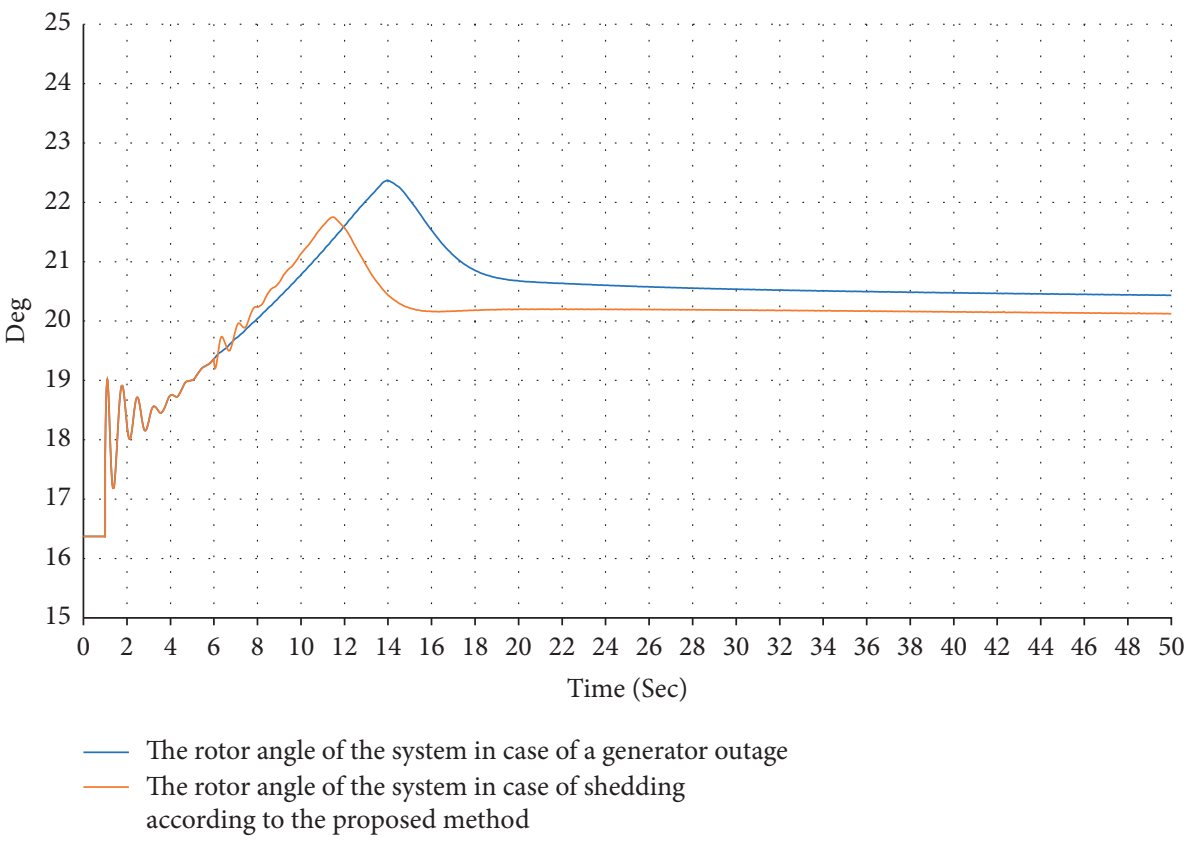

FIGURE 9: Compare the rotor angle when generator outage and when load shedding according to the proposed method.

this case, the problem should only be considered in a range around the "observation area" that is affected by the outage generator. The determination of RPAS and VED will support determining this influence gap. However, the RPAS and
VED values for each grid configuration need to be studied further. At this time, the opinion of the power system expert will support limiting "observation areas" and "inter-observation areas". 


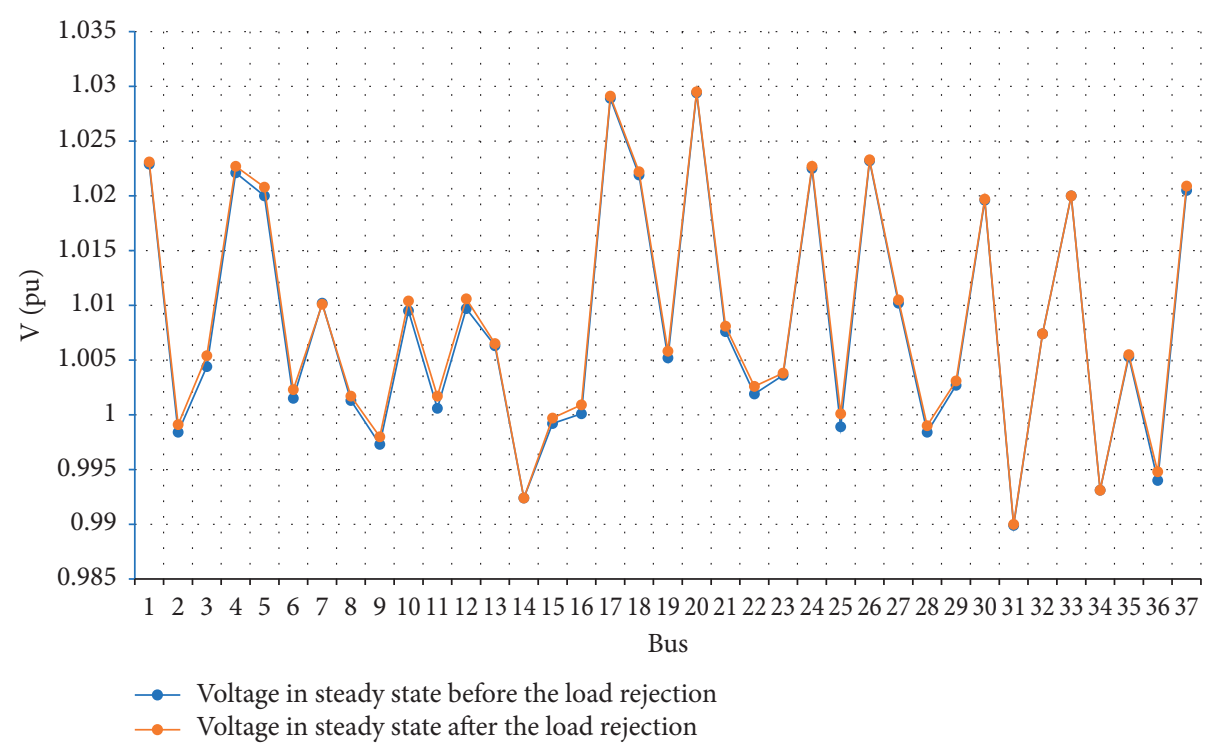

FIgURe 10: Compare the voltage when generator outage and after load shedding according to the proposed method.

\section{Conclusions}

The calculation of overall weights includes the following criteria: Reciprocal Phase Angle Sensitivity (RPAS), Voltage Electrical Distance (VED), and Load Importance Factor (LIF). It ensures multicriteria decision-making that meets economic and technical factors. The analytic hierarchy process algorithm is applied to calculate the weights of the criteria, thereby contributing to combining the weights of the criteria together to determine the combined weight. This weight is used to rank and distributed shedding power to the load buses.

The computation of the amount of load shedding includes the generator control processes that makes the loadshedding power less than the UFLS method and restores the frequency to the allowed value.

The distributed shedding power at each demand load bus based on the overall weights $W$ ensures multimethod coordination of economic and technical criteria and reduces technical and economic losses to power companies and customers.

The efficiency of the suggested approach has been verified on the 37-bus 9-generator system under case studies. This implementation is better than that of the traditional UFLS method. The results proved that the suggested approaches solutions to reduce amount of shedding power while still meeting the technical and economic operating conditions of the network. In future work, the load-shedding scheme should reflect the following aspects minimizing the economic and technical losses of both power companies and customers. To solve this multiobjectives problem, we need to apply algorithms such as genetics algorithm and PSO.

The feasibility of the proposed technique has been shown on the 37-bus system with 9 generators under various experiments. This presentation is superior to that of the traditional UFLS method. The discoveries show that the proposed strategy brings about a decreased measure of load shedding while at the same time fulfilling the specialized technical-economic operating conditions of the network. Later in work, the load-shedding issue ought to consider the accompanying components minimizing the economic and technical losses of both influence organizations and clients. To resolve this multiobjective issue, we need to apply calculations like genetics algorithm and PSO.

\section{Data Availability}

The data of expert opinion in the formulation of the judgment matrix and parameter values and primary control power of the generator used to support the findings of this study are included within the article. The data used to support the findings of this study are available from the corresponding author upon request.

\section{Conflicts of Interest}

The authors declare that they have no conflicts of interest.

\section{Authors' Contributions}

All the authors contributed to the study's conception and design. Topical guidance was performed by Nghia T. Le. Material preparation, data collection, and analysis were performed by An T. Nguyen, Trang H. Thi, Vu Nguyen Hoang Minh, Anh H. Quyen, and Binh T. T. Phan. The first draft of the manuscript was written by Nghia T. Le, and all the authors commented on previous versions of the manuscript. All the authors read and approved the final manuscript.

\section{Acknowledgments}

This work funded by the Ministry of Education and Training and hosted by Ho Chi Minh City University of Technology 
and Education, Vietnam belongs to the project grant no.: B2020-SPK-03.

\section{References}

[1] H. He, F. Peng, Z. Gao et al., "A multi-objective risk scheduling model of an electrical power system-containing wind power station with wind and energy storage integration," Energies, vol. 12, no. 11, 2019.

[2] Florida Reliability Coordinating Council, FRCC Standards Handbook, Florida Reliability Coordinating Council, Florida, FL, USA, 2011.

[3] ERCOT, Underfrequency Load Shedding Assessment and Review, ERCOT, Austin, TX, USA, 2006.

[4] D. U. Hau Aik, "general-order system frequency response model incorporating load shedding analytic modeling and applications," IEEE Transactions on Power Systems, vol. 21, no. 2, 2006.

[5] V. V. Terzija, "Adaptive under frequency load shedding based on the magnitude of the disturbance estimation," IEEE Transactions on Power Systems, vol. 21, no. 3, 2006.

[6] J. A. Laghari, H. Mokhlis, A. H. A. Bakar, and H. Mohamad, "Application of computational intelligence techniques for load shedding in power systems: a review," Energy Conversion and Management, vol. 75, pp. 130-140, 2013.

[7] IEEE Standard, IEEE Guide for the Application of Protective Relays Used for Abnormal Frequency Load Shedding and Restoration, , pp. 41-43, IEEE Std C37117, 2007.

[8] B. Potel, D. Vincent, F. Cadoux, and R. Urban, "A real-time adjustment of conventional under-frequency load shedding thresholds," IEEE Transactions on Power Delivery, vol. 34, no. 6, 2019.

[9] V. Pavlovsky, S. Anton, O. Lenga, V. Zaychenko, and M. Vyshnevskyi, "Frequency stability simulation considering underfrequency load shedding relays, special protection automatics and AGC software models," in Proceedings of the IEEE Manchester PowerTech, Manchester, UK, June 2017.

[10] S. V. Kolluri, J. R. Ramamurthy, S. M. Wong, M. Peterson, P. Yu, and M. R. Chander, "Relay-based undervoltage load shedding scheme for Entergy's western region," in Proceedings of the IEEE Power \& Energy Society General Meeting, Denver, CO, USA, July 2015.

[11] B. Vyakaranam, N. Samaan, M. Vallem et al., "Modeling of protection relays using generic models in system-wide power system dynamic simulation studies," in Proceedings of the 2018 IEEE Power \& Energy Society General Meeting (PESGM), Portland, OR, USA, August2018.

[12] J. Tang, J. Liu, F. Ponci, and A. Monti, "Adaptive load shedding based on combined frequency and voltage stability assessment using synchrophasor measurements," IEEE Transactions on Power Systems, vol. 28, no. 2, pp. 2035-2047, 2013.

[13] M. Hosein Fazaeli, S. S. Aghaee, H. Nafisi, S. Hossein Askarian Abyaneh, and H. Hosseinian, "Under frequency load shedding by considering instantaneous voltage and priority of loads," in Proceedings of the 2017 Conference on Electrical Power Distribution Networks Conference (EPDC), Semnan, Iran, April 2017.

[14] B. D. N. Nascimento, A. C. Z de Souza, J. G. de Carvalho Costa, and M. Castilla, "Load shedding scheme with under-frequency and undervoltage corrective actions to supply high priority loads in islanded microgrids," IET Renewable Power Generation, vol. 13, no. 11, 2019.
[15] D. Lopez and L. Sigrist, "A centralized UFLS scheme using decision trees for small isolated power systems," IEEE Latin America Transactions, vol. 15, no. 10, 2017.

[16] A. Derviškadić, Y. Zuo, G. Frigo, and M. Paolone, "Under frequency load shedding based on pmu estimates of frequency and ROCOF," in Proceedings of the IEEE PES Innovative Smart Grid Technologies Conference Europe (ISGT-Europe), Espoo, Finland, October 2018.

[17] S. S. Banijamali and T. Amraee, "Semi-adaptive setting of under frequency load shedding relays considering credible generation outage scenarios," IEEE Transactions on Power Delivery, vol. 34, no. 3, 2018.

[18] J. Yan, C. Li, and Y. Liu, "Adaptive load shedding method based on power imbalance estimated by ANN," in Proceedings of the TENCON 2017 - 2017 IEEE Region 10 Conference, Penang, Malaysia, November 2017.

[19] Y. Wang, Y. Wang, Y. Ding, Y. Zhou, and Z. Zhang, "A fast load-shedding algorithm for power system based on artificial neural network," in Proceedings of the 2019 International Conference on IC Design and Technology (ICICDT), Suzhou, China, June 2019.

[20] C. Kim, K. Kim, P. Balaprakash, and M. Anitescu, "Graph convolutional neural networks for optimal load shedding under line contingency," in Proceedings of the 2019 IEEE Power \& Energy Society General Meeting (PESGM), Atlanta, GA, USA, August 2019.

[21] Y. Xiao, R. Zhao, and Y. Wen, "Deep learning for predicting the operation of under-frequency load shedding systems," in Proceedings of the 2019 IEEE Innovative Smart Grid Technologies - Asia (ISGT Asia), Chengdu, China, May 2019.

[22] A. M. A. Haidar, A. Mohamed, and A. Hussain, "Vulnerability control of large scale interconnected power system using neuro-fuzzy load shedding approach," Expert Systems with Applications, vol. 37, no. 4, pp. 3171-3176, 2010.

[23] A. K. Bikas, E. M. Voumvoulakis, and N. D. Hatziargyriou, "Neuro-fuzzy decision trees for dynamic security control of power systems," in Proceedings of the Intelligent System Applications to Power Systems, 2009.

[24] B. de Nadai, A. C. Zambroni de Souza, J. A. da Silva Neto, J. G. de Carvalho Costa, F. M. Portelinha, and D. Marujo, “An offline fuzzy-based decision-making to load shedding in microgrids," in Proceedings of the 2019 IEEE PES Innovative Smart Grid Technologies Conference - Latin America (ISGT Latin America), Gramado, Brazil, September 2019.

[25] K. Narayanan, S. Ahmed Siddiqui, and M. Fozdar, "Hybrid islanding detection method and priority-based load shedding for distribution networks in the presence of DG units," IET Generation, Transmission \& Distribution, vol. 11, no. 3, 2017.

[26] M. K. Gray and W. G. Morsi, "Application of PSO and fuzzy logic for underfrequency load shedding," in Proceedings of the 2013 IEEE Electrical Power \& Energy Conference, Nova Scotia, Canada, August 2013.

[27] T. Xu, C. Li, Y. Liu et al., "Optimization of emergency load shedding based on cultural particle swarm optimization algorithm," in Proceedings of the 2019 IEEE Congress on Evolutionary Computation (CEC), Wellington, New Zealand, June 2019.

[28] A. M. A. Haidar, A. Mohamed, A. Hussain, and N. Jaalam, "Artificial Intelligence application to Malaysian electrical power system," Expert Systems with Applications, vol. 37, no. 7, pp. 5023-5031, 2010.

[29] Y. Fan, X. Zi, J. Liu, and B. Lu, "Research on optimal load shedding for active distribution network based on genetic algorithm," in Proceedings of the 2017 2nd International 
Conference on Power and Renewable Energy (ICPRE), Chengdu, China, September 2017.

[30] D. Zhang, W. Li, Z. Jiang, N. Wu, and Y. Hou, "Load shedding strategy coordinate optimization based on sensitivity analysis," in Proceedings of the 2016 IEEE PES Asia-Pacific Power and Energy Engineering Conference (APPEEC), December 2016.

[31] L. C. Ung, "AHP approach for load shedding scheme of an islanded power system," Master's Thesis, University Tun Hussein Onn Malaysia, Parit Raja, Malaysia, 2012.

[32] G. H. Hwang, "Application of Analytic Hierarchy Process (AHP) in load shedding scheme for electrical power system," in Proceedings of the International Conference on Environment and Electrical Engineering, vol. 9, pp. 365-368, Prague, Czech Republic, June 2010.

[33] J. Zhu, Optimization of Power System Operation, 2015.

[34] T. N. L. H. Anh Quyen and A. N. Nguyen, "Application of fuzzy-analytic hierarchy process algorithm and fuzzy load profile for load shedding in power systems," Electrical Power and Energy Systems, vol. 77, pp. 178-184, 2016.

[35] L. Patrick, "The different electrical distance," in Proceedings of the Tenth Power Systems Computation Conference, Graz, Austria, August 1990.

[36] C. Paul and K. Andrew, "Visualizing the electrical structure of power systems," IEEE Systems Journal, vol. 11, no. 3, pp. 1810-1821, 2017.

[37] T. N. E. Greville, "Some applications of the pseudoinverse of a matrix," SIAM Review, vol. 2, no. 1, pp. 15-22, 1960.

[38] E. Cotilla-Sanchez, P. D. H. Hines, C. Barrows, S. Blumsack, and M. Patel, "Multi-attribute partitioning of power networks based on electrical distance," IEEE Transactions on Power Systems, vol. 28, no. 4, pp. 4979-4987, 2013.

[39] D. J. Klein and M. Randić, "Resistance distance," Journal of Mathematical Chemistry, vol. 12, no. 1, pp. 81-95, 1993.

[40] S.-H. Song, Y. T. Y. Ho-Chul Lee, and S.-Il Moon, "Cluster design compatible with market for effective reactive power management," in Proceedings of the IEEE Power Engineering Society General Meeting, Montreal, Canada, June 2006.

[41] H. Nemouchi, T. Ahmed, and A. L. Ahmed, "An adaptive decentralized under voltage load shedding in distribution networks," International transactions on Electrical Energy System, vol. 30, no. 11, 2020.

[42] L. T. Nghia, Q. H. Anh, H. T. T. Hien, P. T. T. Binh, and L. T. nhan, "Load shedding apply neural network and voltage electrical distance," International Journal of Engineering Research and Technology, vol. 07, no. 06, 2018.

[43] P. Lagonotte, J. C. Sabonnadiere, J.-Y. Leost, and J.-P. Paul, "Structural analysis of the electrical system: application to secondary voltage control in France," IEEE Transactions on Power Systems, vol. 4, no. 2, pp. 479-486, 1989.

[44] T. L. Saaty, "How to make a decision: the analytic hierarchy process," INFORMS Journal on Applied Analytics, vol. 24, no. 6, pp. 19-43, 1994.

[45] W. Sam, R. D’Hulst, and J. Driesen, "Primary and secondary frequency support by a multi-agent demand control system," IEEE Transactions on Power Systems, vol. 30, no. 3, pp. 1394-1404, 2015.

[46] E. Dvorský, L. Raková, and P. Hejtmánková, "Primary and secondary frequency regulation with photovoltaic generators," in Proceedings of the 2015 16th International Scientific Conference on Electric Power Engineering (EPE), May 2015.

[47] T. N. Le, Q. Huy Anh, P. T. Thanh Binh, and P. T. Tan, "Minimize the load reduction considering the activities control of the generators and phase distance," International
Journal of Electrical and Computer Engineering, vol. 11, pp. 993-1001, 2021.

[48] J. Allen and G. B. Sheblé, Power Generation, Operation and Controlpp. 473-481, John Wiley \& Sons, New York, NY, USA, Third edition, 2014.

[49] J. Duncan Glover, M. S. Sarma, and T. J. Overbye, Power System Analysis and Designp. 718, Sixth edition, Cengage Learning, Boston, MA, USA, 2017.

[50] W. Pedrycz and M. Song, "Analytic hierarchy process (AHP) in group decision making and its optimization with an allocation of information granularity," IEEE Transactions on Fuzzy Systems, vol. 19, no. 3, pp. 527-539, June 2011. 